\title{
Randomized controlled trial of vacuum therapy for intermittent claudication
}

Citation for published version (APA):

Hageman, D., Fokkenrood, H. J. P., van Deursen, B. A. C., Gommans, L. N. M., Cancrinus, E., Scheltinga, M. R. M., \& Teijink, J. A. W. (2020). Randomized controlled trial of vacuum therapy for intermittent claudication. Journal of Vascular Surgery, 71(5), 1692-1701.e1.

https://doi.org/10.1016/j.jvs.2019.08.239

Document status and date:

Published: 01/05/2020

DOI:

10.1016/j.jvs.2019.08.239

Document Version:

Publisher's PDF, also known as Version of record

Document license:

Taverne

Please check the document version of this publication:

- A submitted manuscript is the version of the article upon submission and before peer-review. There can be important differences between the submitted version and the official published version of record.

People interested in the research are advised to contact the author for the final version of the publication, or visit the DOI to the publisher's website.

- The final author version and the galley proof are versions of the publication after peer review.

- The final published version features the final layout of the paper including the volume, issue and page numbers.

Link to publication

\footnotetext{
General rights rights.

- You may freely distribute the URL identifying the publication in the public portal. please follow below link for the End User Agreement:

www.umlib.nl/taverne-license

Take down policy

If you believe that this document breaches copyright please contact us at:

repository@maastrichtuniversity.nl

providing details and we will investigate your claim.
}

Copyright and moral rights for the publications made accessible in the public portal are retained by the authors and/or other copyright owners and it is a condition of accessing publications that users recognise and abide by the legal requirements associated with these

- Users may download and print one copy of any publication from the public portal for the purpose of private study or research.

- You may not further distribute the material or use it for any profit-making activity or commercial gain

If the publication is distributed under the terms of Article $25 \mathrm{fa}$ of the Dutch Copyright Act, indicated by the "Taverne" license above, 


\title{
Randomized controlled trial of vacuum therapy for intermittent claudication
}

\author{
David Hageman, MD, ${ }^{a, b}$ Hugo J. P. Fokkenrood, MD, PhD, ${ }^{c}$ Brit A. C. van Deursen, BSc, ${ }^{a}$ \\ Lindy N. M. Gommans, MD, PhD, ${ }^{a}$ Ernst Cancrinus, MD, ${ }^{d}$ Marc R. M. Scheltinga, MD, PhD, ${ }^{e}$ and \\ Joep A. W. Teijink, MD, PhD, a,b Eindhoven, Maastricht, Nijmegen, Geldrop, and Veldhoven, The Netherlands
}

\begin{abstract}
Objective: The "gold standard" treatment of intermittent claudication (IC) is supervised exercise therapy (SET). Intermittent vacuum therapy (IVT) has recently been promoted as an additional treatment of IC. During IVT, negative pressure and atmospheric pressure are alternatingly applied to the lower extremities, possibly resulting in improved circulation. The aim of this study was to determine a potential additional effect of IVT in IC patients undergoing a standardized SET program.

Methods: IC patients were recruited from three Dutch general hospitals between December 2015 and July 2017. They received a standardized SET program but were also randomly assigned to an intervention group receiving an IVT treatment ( $-50 \mathrm{mBar}$ negative pressure) or a control group receiving a sham treatment ( $-5 \mathrm{mBar}$ negative pressure). IVT was provided in a dedicated clinic during 12 sessions of 30 minutes during a 6-week period. The primary outcome measure was a change in maximal treadmill walking distance. Secondary outcome measures were a change in functional treadmill walking distance, 6-minute walk test, ambulatory ability, and quality of life.

Results: A total of 78 patients were randomized, of whom 70 were available for intention-to-treat analysis (control, $n=34$; intervention, $\mathrm{n}=36$ ). At 6 and 12 weeks, increases in walking distance were of equal magnitude. Median (interquartile range) change in maximal treadmill walking distance during 12 weeks was +335 (205-756) meters in control patients and +250 (77-466) meters in intervention patients $(P=.109)$, whereas functional treadmill walking distance increased +230 (135-480) meters and +188 (83-389) meters $(P=.233)$, respectively. Mean \pm standard deviation change in the 6-minute walk test was $+36 \pm 48$ meters and $+55 \pm 63$ meters $(P=.823)$, respectively. Ambulatory ability and quality of life improved equally in both groups.
\end{abstract}

Conclusions: IVT does not confer any additional beneficial effects in IC patients undergoing a standardized SET program. (J Vasc Surg 2020;71:1692-701.)

Keywords: Peripheral artery disease; Intermittent claudication; Supervised exercise therapy; Vacuum therapy; Negative pressure therapy; Randomized controlled trial

Peripheral artery disease (PAD) is prevalent in 202 million people worldwide and affects $15 \%$ to $20 \%$ of individuals older than 70 years. Intermittent claudication (IC) is the most frequent symptom of PAD and is

From the Department of Vascular Surgery, Catharina Hospital, Eindhoven ${ }^{\mathrm{a}}$; the Department of Epidemiology, CAPHRI School for Public Health and Primary Care, Faculty of Health, Medicine and Life Sciences, Maastricht University, Maastricht ${ }^{\mathrm{b}}$; the Department of Vascular Surgery, Radboud University Medical Center, Nijmegen ${ }^{c}$; the Department of Vascular Surgery, St. Anna Hospital, Geldrop $^{d}$; and the Department of Vascular Surgery, Máxima Medical Center, Veldhoven. ${ }^{\text {e }}$

Clinical trial registration: NTR6353.

Author conflict of interest: none.

Additional material for this article may be found online at www.jvascsurg.org.

Correspondence: Joep A.W. Teijink, MD, PhD, Department of Vascular Surgery,

Catharina Hospital, PO Box 1350, 5602 ZA Eindhoven, The Netherlands (e-mail: joep.teijink@catharinaziekenhuis.nl).

The editors and reviewers of this article have no relevant financial relationships to disclose per the JVS policy that requires reviewers to decline review of any manuscript for which they may have a conflict of interest.

0741-5214

Copyright $\odot 2019$ by the Society for Vascular Surgery. Published by Elsevier Inc. https://doi.org/10.1016/j.jvs.2019.08.239 associated with ambulatory dysfunction and poor health status. The "gold standard" treatment of IC is supervised exercise therapy (SET) combined with cardiovascular risk management (CVRM). ${ }^{2-4}$ Multiple randomized controlled trials (RCTs) and meta-analyses have demonstrated the efficacy of SET regarding an improved walking distance and health-related quality of life. ${ }^{5-10}$ Limb revascularization, such as angioplasty or bypass surgery, is currently considered only in patients who fail to favorably respond to SET.

A number of alternative strategies possibly improving the functional impairment associated with lower extremity ischemia by increasing blood flow have hitherto been explored but often to no avail. Vacuum therapy is commonly used to treat wounds by applying negative pressure to the local tissue environment to remove excessive fluid. ${ }^{11,12}$ A variant termed intermittent vacuum therapy (IVT) has recently been promoted by commercial parties in a number of European countries as an additional treatment of IC. ${ }^{13,14}$ During IVT, negative pressure and atmospheric pressure are alternatingly applied to 
the lower extremities. By doing so, it is speculated that a rhythmic vascular dilation and compression are created that may stimulate circulation and may subsequently improve walking distances and reduce pain. Recently, IVT applied to the lower leg and foot increased foot perfusion in healthy volunteers and patients with PAD. ${ }^{15,16}$ However, it is unknown whether IVT exerts any positive clinical effects in patients with IC.

The aim of this study was to determine a potential additional effect of IVT in IC patients undergoing a standardized SET program.

\section{METHODS}

\section{Patient recruitment}

This RCT was a combined effort of vascular surgery outpatient departments of three Dutch general hospitals (Catharina Hospital, Eindhoven [ $=34$ ]; Máxima Medical Center, Veldhoven [ $=32$ ]; and St. Anna Hospital, Geldrop $[n=12])$ between December 2015 and July 2017. The study was evaluated and approved by the Institutional Review Board of the Catharina Hospital, Eindhoven, The Netherlands, and reported according to the Consolidated Standards of Reporting Trials guidelines. ${ }^{17}$ Written informed consent was obtained from each patient before enrollment. Demographic information, height, weight, body mass index, cardiovascular risk factors, comorbid conditions, claudication history, and ankle-brachial indices were obtained at the start of the study.

\section{Inclusion and exclusion criteria}

Patients with IC (Fontaine stage II/Rutherford class 1-3) were eligible. The diagnosis of lower limb PAD was based on an ankle-brachial index of $<0.9$ at rest or a drop of $>0.15$ after exercise. ${ }^{2-4}$ Patients were included if they had an indication for treatment with SET, sufficient additional insurance or adequate financial resources for a SET program of 1 year, and motivation to participate in the study (particularly additional travel time investment for treatment with IVT) and provided informed consent. They were excluded if they had a maximal walking distance of $>1000$ meters at baseline as assessed with a graded treadmill test, ${ }^{18}$ inability to complete 12 IVT sessions in the first 12 weeks, prior treatment of PAD in the previous 2 years (conservative or invasive treatment), prior treatment with IVT, cognitive disabilities, inadequate mastering of the Dutch language, contraindications to IVT (pregnancy, infection or inflammation of the lower limbs, abdominal wall hernia), critical limb ischemia, recent ( $<6$ weeks) trauma of the lower limbs, and severe hip or knee osteoarthritis and planned joint replacement therapy. Patient flow is shown in Fig 1.

\section{Randomization and blinding}

Participants were randomly assigned to IVT intervention or sham control. Randomization occurred using a computer-generated randomization list and was

\section{ARTICLE HIGHLIGHTS}

Type of Research: Multicenter, randomized controlled trial

- Key Findings: Intermittent vacuum therapy (IVT) did not lead to any additional beneficial effects on walking distance, self-reported ambulatory ability, or health-related quality of life in 78 patients with intermittent claudication who were treated with a standardized supervised exercise therapy program.

- Take Home Message: IVT should not be offered to intermittent claudication patients as adjunctive therapy. Further studies on any potential mechanisms and clinical implications of IVT are needed.

executed by a researcher who was not involved in the recruitment or data-gathering process. Moreover, all participants received usual care consisting of SET and CVRM. Vascular surgeons, supervising physical therapists who assessed outcome measures, and participants were blinded to group allocation. Staff at the IVT facility was not blinded to group allocation, inherent to the study design.

\section{Interventions}

Usual care: SET and CVRM. All participants received usual care including a standardized SET program provided by a certified physical therapist affiliated with ClaudicatioNet, a nationwide community-based network for SET and lifestyle coaching in The Netherlands. ${ }^{19-21}$ The SET program was set up to improve walking distance as reported earlier..$^{5-8}$ Our program consists of 1 year of supervised, intermittent treadmill walking to near-maximal claudication pain. Patients generally start with two or three sessions of 30 minutes weekly. Volume and intensity are tailored to the individual needs of the patient during the treatment year. All physical therapists provided SET according to the guidelines of the Royal Dutch Society for Physical Therapy. ${ }^{22}$ As part of this SET program, all participants were encouraged to also perform additional exercise in their spare time. In line with clinical practice guidelines, they also received best medical therapy including smoking cessation and antiplatelet and lipid-lowering therapy. ${ }^{2-4}$ Best medical therapy was customized to individual risk factors, such as hypertension, hypercholesterolemia, and diabetes mellitus (DM).

IVT. IVT treatment was performed in a dedicated clinic (Been Kliniek, Eindhoven, The Netherlands) with a Vacumed device (Weyergans High Care AC, Dueren, Germany). The device consists of an airtight vacuum chamber and a pump connected to a pressure control system. During IVT treatments, participants were asked to lay themselves comfortably in a supine position (Fig 2). The lower body was positioned in the vacuum 


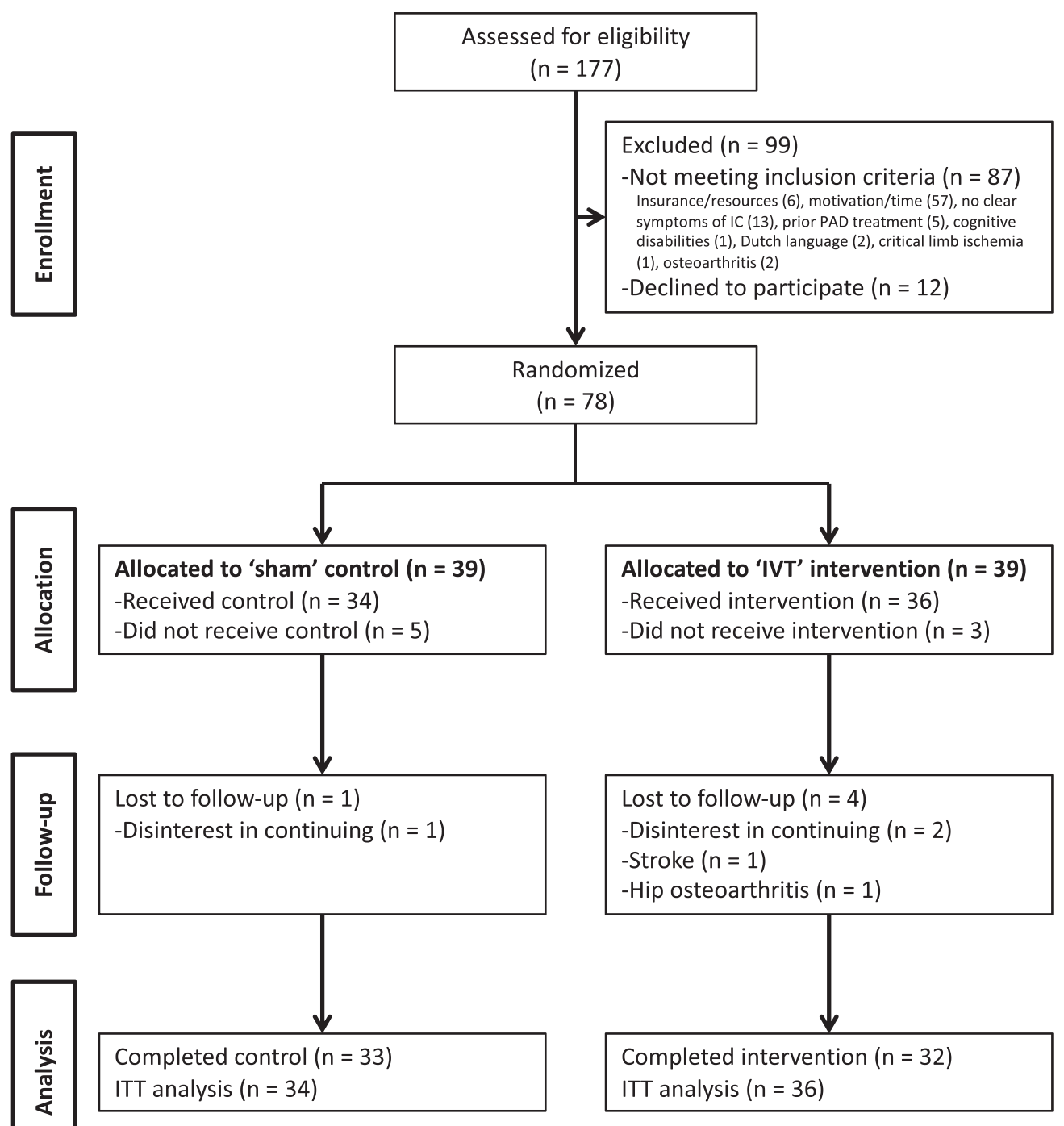

Fig 1. Flow diagram of selection of patients. IC, Intermittent claudication; ITT, intention-to-treat; IVT, intermittent vacuum therapy; $P A D$, peripheral artery disease.

chamber, which was sealed around the participant's trunk with a cuff at the level of the umbilicus to allow application of negative pressure. Negative pressure cycles are created by alternating between removing air and venting the chamber to atmospheric pressure. During IVT treatments, a PAD-specific treatment program was started at the press of a button. IVT was applied using an oscillation protocol with cycles of 9 seconds of negative pressure and 9 seconds of atmospheric pressure. These preprogrammed settings were based on the experience of both the manufacturer and the IVT facility.

Patients randomized to the intervention group received an IVT treatment with a negative pressure of $-50 \mathrm{mBar}$ $(-37.5 \mathrm{~mm} \mathrm{Hg})$. Patients randomized to the control group received a sham treatment with a negative pressure of $-5 \mathrm{mBar}(-3.75 \mathrm{~mm} \mathrm{Hg})$. To put these pressures in context, the intrapleural pressure is $-5 \mathrm{mBar}$ under static conditions and $-20 \mathrm{mBar}$ during a vigorous inspiration. A typical domestic vacuum cleaner has a suction of about $-200 \mathrm{mBar}$. The control group treatment was designed to be as similar as possible to the intervention group treatment in an attempt to control for the potentially confounding effects of attention and social contact, placebo, and Hawthorne effects of IVT. It was supposed to mimic the experience of undergoing negative pressure without exposing the participant to a possible effective IVT treatment.

Both groups received 12 IVT sessions of 30 minutes during a 6-week period (two per week). IVT treatment started within 1 week after enrollment. No exercise was performed by the participants in the IVT facility during these treatments. However, all participants were encouraged to have an IVT session followed by a SET session on the same day.

To quantify the amount of treatment performed in the intervention and control groups, IVT and SET sessions 


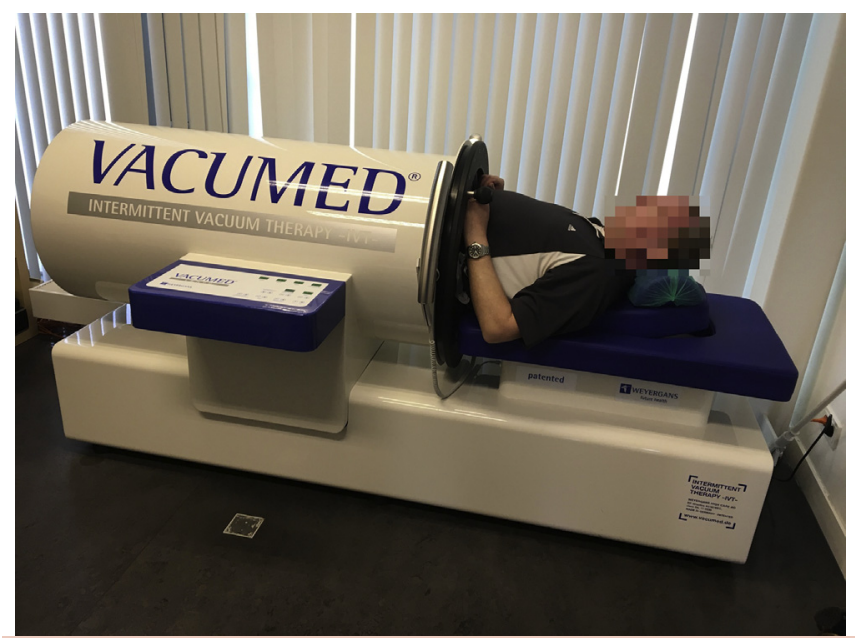

Fig 2. Vacumed device (Weyergans High Care AG, Dueren, Germany). The participant's lower body is positioned in an airtight vacuum chamber interfaced with the pressure control system. The chamber is sealed around the participant's trunk at the level of the umbilicus.

were recorded in a logbook by the research staff. The manufacturer (Weyergans High Care AG) and staff at the IVT facility (Been Kliniek) did not have access to outcome data and did not participate in data analysis or preparation of the manuscript.

\section{Outcome measures}

The primary outcome measure was a change in maximal treadmill walking distance (MWD). Secondary outcome measures were a change in functional treadmill walking distance (FWD), total distance during the 6-minute walk test (6MWT), self-reported ambulatory ability, and health-related quality of life. Outcome data were obtained by physical therapists at baseline and after 6 weeks and 12 weeks of follow-up.

Graded treadmill test: FWD and MWD. Patients performed a progressive, graded treadmill test (walking speed of $3.2 \mathrm{~km} / \mathrm{h}$ [2.0 mph] and inclination beginning at $0 \%$ grade and increasing by $2 \%$ every 2 minutes) to determine study eligibility and to obtain the outcome measures of FWD and MWD. ${ }^{18}$ For practical reasons, the maximal inclination was 10\%, and the maximal duration was 30 minutes (1600 meters). FWD was defined as the distance at which the patient preferred to stop walking because of claudication pain. MWD was defined as the distance at which the patient had to stop walking because of maximal claudication pain. FWD and MWD are both reliable parameters reflecting walking distance in patients with IC. . $^{23,24}$

6MWT. For self-paced exercise performance measurement, patients performed the overground 6MWT in which two cones were placed 10 meters apart in a marked corridor. ${ }^{25}$ Patients were instructed to walk as many laps as possible around the cones. The total distance during the 6MWT was recorded. The 6MWT yields highly reliable measurements. ${ }^{26}$

Self-reported ambulatory ability. Self-reported ambulatory ability was obtained using the validated Walking Impairment Questionnaire (WIQ) for PAD patients. ${ }^{27}$ It contains three domains to assess walking impairment: walking distance, walking speed, and stair climbing. For each domain, a subscore of the Likert items was calculated. The mean of these domains represents the total WIQ score. The Dutch version of the WIQ using the European metric system is a reliable instrument for assessing walking impairment in patients with IC. ${ }^{28,29}$

Disease-specific quality of life. Disease-specific quality of life was assessed with the Vascular Quality of Life (VascuQol) questionnaire. ${ }^{30}$ The VascuQol consists of 25 items, subdivided into five domains: pain, symptoms, activities, social well-being, and emotional wellbeing. Each item has seven possible options ranging from 1 (worst possible) to 7 (best possible). A summary score, also ranging from 1 to 7 (worst to best), is calculated by adding the score of all items and then dividing the total by 25 . The Dutch VascuQol is a reliable questionnaire for assessment of quality of life in patients with IC. . $^{31,32}$

Generic quality of life. Generic quality of life was assessed with the EuroQol 5-Dimension 3-Level (EQ-5D) instrument. ${ }^{33}$ The EQ-5D consists of a descriptive system and a visual analog scale (VAS). The descriptive system comprises five dimensions: mobility, self-care, usual activities, pain/discomfort, and anxiety/depression. The VAS records the patient's self-rated health on a vertical VAS. These parameters can be used as a quantitative measure of health outcome that reflects the patient's own judgment.

\section{Statistical analysis}

Sample size calculations were performed on the primary outcome measure of MWD. With a sample size of 25 patients per treatment arm, the trial achieved an $80 \%$ power to detect a difference in MWD of $200 \pm 250$ meters using a two-sided independent samples $t$-test and a significance level of $\alpha=.05$. Assuming a $10 \%$ withdrawal rate, 30 patients in each group had to be included.

Categorical variables were presented as frequencies with percentages, and continuous variables were presented as means with standard deviations when normally distributed or as medians with interquartile ranges when non-normally distributed. For baseline characteristics, comparisons between groups were performed using $\chi^{2}$ tests for categorical variables and independent samples $t$-tests for continuous variables. If variables were normally distributed, within-group changes from baseline were analyzed by repeated- 
Table I. Baseline characteristics of intermittent claudication (IC) patients randomized to control or intervention

\begin{tabular}{|c|c|c|c|}
\hline Variables & $\begin{array}{l}\text { Control } \\
(n=39)\end{array}$ & $\begin{array}{l}\text { Intervention } \\
(\mathrm{n}=39)\end{array}$ & $P$ value \\
\hline Male sex & $25(64)$ & $26(67)$ & $1.000^{a}$ \\
\hline Age, years & $68 \pm 9$ & $67 \pm 8$ & $.445^{b}$ \\
\hline Length, $\mathrm{cm}$ & $171 \pm 9$ & $173 \pm 9$ & $.308^{b}$ \\
\hline Weight, kg & $83 \pm 17$ & $82 \pm 14$ & $.812^{b}$ \\
\hline BMI, $\mathrm{kg} / \mathrm{m}^{2}$ & $28 \pm 5$ & $28 \pm 4$ & $.441^{\mathrm{b}}$ \\
\hline $\mathrm{ABI}$ at rest & $0.69 \pm 0.24$ & $0.69 \pm 0.15$ & $.967^{\mathrm{b}}$ \\
\hline $\mathrm{ABI}$ after exercise & $0.39 \pm 0.18$ & $0.40 \pm 0.19$ & $.940^{\circ}$ \\
\hline Symptoms & & & $.473^{a}$ \\
\hline Unilateral & $23(59)$ & $18(46)$ & \\
\hline Bilateral & $16(41)$ & $21(54)$ & \\
\hline Smoking & & & $689^{a}$ \\
\hline Current & $10(26)$ & 7 (18) & \\
\hline Former & 27 (69) & $30(77)$ & \\
\hline Never & $2(5)$ & $2(5)$ & \\
\hline Hypertension & 27 (69) & $29(74)$ & $.802^{a}$ \\
\hline Hypercholesterolemia & $26(67)$ & $17(44)$ & $.068^{a}$ \\
\hline Obesity & $12(31)$ & $12(31)$ & $.800^{a}$ \\
\hline Coronary artery disease & $21(54)$ & $18(46)$ & $.651^{a}$ \\
\hline Congestive heart failure & $9(23)$ & 7 (18) & $.780^{a}$ \\
\hline Atrial fibrillation & $4(10)$ & $2(5)$ & $.675^{\mathrm{a}}$ \\
\hline COPD & $8(21)$ & $8(21)$ & $1.000^{a}$ \\
\hline TIA or CVA & $5(13)$ & $8(21)$ & $.545^{a}$ \\
\hline LE neurologic disease & $5(13)$ & 7 (18) & $.755^{a}$ \\
\hline LE orthopedic disease & $5(13)$ & $5(13)$ & $1.000^{a}$ \\
\hline Renal insufficiency & $6(15)$ & $4(10)$ & $.737^{a}$ \\
\hline DM & $5(13)$ & $13(33)$ & $.058^{a}$ \\
\hline History of PAD & $11(28)$ & $14(36)$ & $.628^{a}$ \\
\hline Prior SET & $2(5)$ & $3(8)$ & $1.000^{a}$ \\
\hline Prior ER & $11(28)$ & $8(21)$ & $.599^{a}$ \\
\hline Prior SR & $2(5)$ & $4(10)$ & $.675^{a}$ \\
\hline \multicolumn{4}{|c|}{$\begin{array}{l}\text { ABI, Ankle-brachial index; } B M I, \text { body mass index; } C O P D \text {, chronic } \\
\text { obstructive pulmonary disease; } C V A \text {, cerebrovascular accident; } D M \text {, } \\
\text { diabetes mellitus; ER, endovascular revascularization; } L E \text {, lower } \\
\text { extremity; } P A D \text {, peripheral artery disease; SET, supervised exercise } \\
\text { therapy; } S R \text {, surgical revascularization; TIA, transient ischemic attack. } \\
\text { Categorical variables are presented as number (\%). Continuous vari- } \\
\text { ables are presented as mean } \pm \text { standard deviation. } \\
{ }^{a} \chi^{2} \text { test. } \\
{ }^{b} \text { Independent samples } t \text {-test. }\end{array}$} \\
\hline
\end{tabular}

measures analysis of variance, and between-group differences were analyzed by univariate analysis of covariance, controlling for baseline data. If variables were nonnormally distributed, within-group changes from baseline were analyzed using the Friedman test, and between-group differences were analyzed using the Mann-Whitney $U$ test.

All participants were included in the statistical analysis of baseline, 6-week, and 12-week follow-up data, which was done on an intention-to-treat (ITT) basis. Missing values (3\%) were estimated by multiple imputation. To investigate the influence of attrition patterns on study results, all analyses were repeated with the completer data only (excluding imputed data). All analyses were performed with SPSS 24 software (IBM Corp. Armonk, NY). Graphs were created with GraphPad Prism 6 software (GraphPad Software Inc, La Jolla, Calif). Statistical significance was defined as $P<.05$.

\section{RESULTS}

Study population. A total of 177 patients were assessed for eligibility, of whom 87 did not meet inclusion criteria (mainly for logistical reasons, lack of time or motivation to travel to and from the IVT facility) and 12 declined to participate, leaving 78 patients (44\%) for randomization (Fig 1). Randomization resulted in similar $(P>.05)$ baseline characteristics of the groups (Table I). However, there was a trend toward a higher incidence of DM in the intervention group compared with the control group (33\% and 13\%, respectively; $P=.058$ ). Eight patients (control, $\mathrm{n}=5$; intervention, $\mathrm{n}=3$ ) had an exercise performance not limited by claudication as determined by treadmill testing. Based on eligibility criteria, these patients did not start with the study, leaving 70 patients for ITT analysis.

Follow-up. In total, 65 patients (93\%; control, $n=33$; intervention, $\mathrm{n}=32$ ) completed the program. Five patients (7\%; control, $n=1$; intervention, $n=4$ ) discontinued the program before the 12-week end point. The primary reason for discontinuing the program was lack of interest. Two patients in the intervention group discontinued because of an adverse event not related to the study (one stroke and one hip osteoarthritis). Missing data from the five patients who did not complete the study were imputed. Baseline characteristics remained similar between the groups $(P>.05)$ after inclusion of only the 65 patients who completed the study (data not shown). Furthermore, no significant group difference was noted for number of dropouts $(P=.185)$. At 12 weeks of follow-up, no patient had undergone limb revascularization (eg, angioplasty or bypass surgery).

Adherence to the IVT and SET program. The number of completed treatment sessions in the two groups was similar $(P>.05)$. Patients in both groups completed 12 IVT sessions within a median of 5.5 (5.4-5.8) weeks, except for one control patient who stopped the IVT treatment after three sessions for personal reasons. Based on the ITT principle, this patient was included in the analysis. In addition, control patients completed a median of 21 (17-23) SET sessions within 12 weeks, and intervention patients completed a median of 23 (19-25) SET sessions $(P=.064)$.

Walking distances. Both groups demonstrated comparable $(P>.05)$ walking distances at all time points (Figs 3-5). MWD and FWD increased in both groups (all 


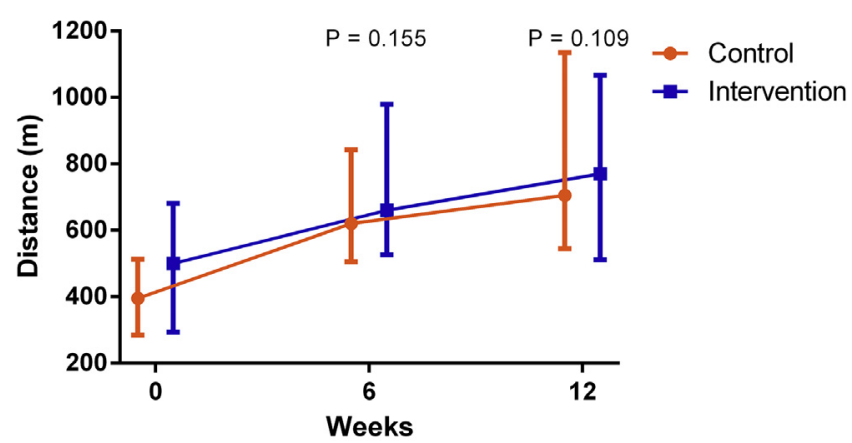

Fig 3. Median maximal treadmill walking distance (MWD) at baseline and after 6 and 12 weeks in the control and intervention groups. The error bars represent interquartile range. $P$ values represent difference in change from baseline between groups.

$P<.001$ ). At 6 weeks, median (interquartile range) change in MWD was +223 (129-430) meters in the control group and +191 (63-328) meters in the intervention group $(P=.155)$, whereas FWD increased +229 (102-345) meters and +180 (75-288) meters $(P=.359)$, respectively. At 12 weeks, change in MWD was +335 (205-756) meters in the control group and +250 (77-466) meters in the intervention groups $(P=.109)$, whereas FWD increased +230 (135-480) meters and +188 (83-389) meters $(P=.233)$, respectively. Analysis of 6MWT data indicated that total distance increased in both groups from baseline to 6 weeks (both $P<.001$ ) but did not change from 6 to 12 weeks (both $P>$.05). At 6 weeks, mean \pm standard deviation change in 6MWT was $+34 \pm 40$ meters in the control group and $+44 \pm 80$ meters in the intervention group $(P=.896)$. At 12 weeks, $6 \mathrm{MWT}$ increased $+36 \pm$ 48 meters and $+55 \pm 63$ meters $(P=.823)$, respectively. When analyses were repeated with the completer data only (excluding imputed data), findings were unchanged (data not shown). This indicates that attrition patterns had minimal influence on study results.

To determine whether IVT has differential effects per baseline walking distance, the intervention group was subdivided into a short-distance subgroup (baseline MWD $<$ median) and a long-distance subgroup (baseline MWD $\geq$ median). However, no differences regarding change from baseline between subgroups were found after 6 weeks (short, +195 [60-290] meters; long, +188 [73-388] meters; $P=.759$ ) and 12 weeks (short, +196 [62-375] meters; long, +289 [98-648] meters; $P=.271$ ). Furthermore, after adjustment for DM in a multivariate regression analysis, no significant group effects regarding MWD were found after 6 weeks $(\beta \pm$ standard error $=-86 \pm 66 ; P=.191)$ or 12 weeks $(\beta \pm$ standard error $=-131 \pm 82 ; P=.108)$.

WIQ. Groups were similar $(P>.05)$ at baseline and after 6 and 12 weeks of follow-up on each WIQ measure. Total WIQ score and distance and speed domains improved in both groups, whereas the stair domain improved in the

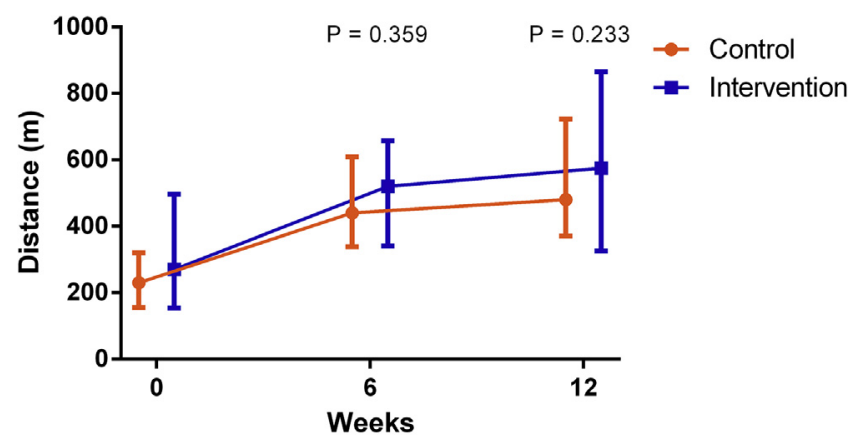

Fig 4. Median functional treadmill walking distance (FWD) at baseline and after 6 and 12 weeks in the control and intervention groups. The error bars represent interquartile range. $P$ values represent difference in change from baseline between groups.

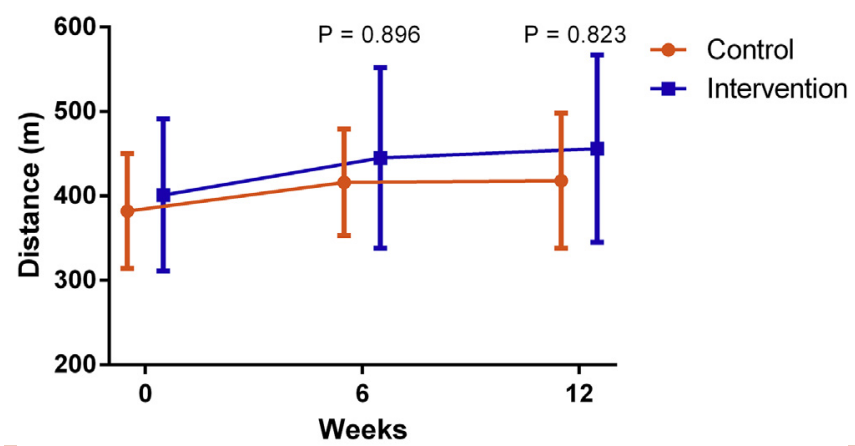

Fig 5. Mean 6-minute walk test (6MWT) at baseline and after 6 and 12 weeks in the control and intervention groups. The error bars represent standard deviations. $P$ values represent difference in change from baseline between groups.

intervention group only (Table II). However, changes in the intervention group were not significantly different $(P$ $>$.05) from those in the control group.

Health-related quality of life. Groups were similar $(P>.05)$ at baseline and after 6 and 12 weeks of followup on each health-related quality of life measure. Summary VascuQol score, pain, symptoms, activities, and emotional domains improved in both groups, whereas the social domain improved in the intervention group only (Table III). However, changes in the intervention group were not significantly different $(P>.05)$ from those in the control group. The EQ-5D index and VAS score remained unaltered (data not shown).

\section{DISCUSSION}

The aim of this study was to determine a potentially beneficial effect of IVT in IC patients undergoing a standardized SET program. The execution of this RCT was prompted by unauthorized claims of commercial parties that IVT is highly effective in the treatment of IC. . $^{13,14}$ Both groups improved walking distance, self-reported 
Table II. Walking impairment questionnaire (WIQ)

\begin{tabular}{|c|c|c|c|c|c|c|c|c|}
\hline Variables & Baseline & 6 weeks & 12 weeks & $\begin{array}{l}P \text { value } \\
\text { within } \\
\text { groups }\end{array}$ & $\begin{array}{l}\text { Change } \\
\text { from } \\
\text { baseline to } \\
6 \text { weeks }\end{array}$ & $\begin{array}{l}P \text { value } \\
\text { between } \\
\text { groups }\end{array}$ & $\begin{array}{l}\text { Change } \\
\text { from } \\
\text { baseline to } \\
12 \text { weeks }\end{array}$ & $\begin{array}{l}P \text { value } \\
\text { between } \\
\text { groups }\end{array}$ \\
\hline \multicolumn{9}{|l|}{ Total score } \\
\hline Control & $0.48 \pm 0.18$ & $0.55 \pm 0.16$ & $0.58 \pm 0.19$ & .004 & $0.07 \pm 0.15$ & .266 & $0.10 \pm 0.14$ & .741 \\
\hline Intervention & $0.51 \pm 0.18$ & $0.61 \pm 0.15$ & $0.63 \pm 0.18$ & $<.001$ & $0.10 \pm 0.15$ & & $0.13 \pm 0.13$ & \\
\hline Control & $0.36 \pm 0.23$ & $0.48 \pm 0.23$ & $0.48 \pm 0.26$ & .011 & $0.12 \pm 0.22$ & .542 & $0.12 \pm 0.23$ & .798 \\
\hline Intervention & $0.40 \pm 0.23$ & $0.54 \pm 0.22$ & $0.57 \pm 0.27$ & $<.001$ & $0.15 \pm 0.21$ & & $0.18 \pm 0.21$ & \\
\hline \multicolumn{9}{|l|}{ Speed } \\
\hline Control & $0.48 \pm 0.21$ & $0.55 \pm 0.17$ & $0.60 \pm 0.19$ & 011 & $0.06 \pm 0.19$ & .431 & $0.12 \pm 0.21$ & .646 \\
\hline Intervention & $0.47 \pm 0.19$ & $0.54 \pm 0.16$ & $0.56 \pm 0.17$ & .030 & $0.07 \pm 0.21$ & & $0.09 \pm 0.18$ & \\
\hline
\end{tabular}

ambulatory ability, and health-related quality of life after a regimen of SET. However, the additive effect of IVT was nil.

Reports on the application of "suction devices" to the lower limb for the treatment of PAD date back to the 20th century. Initial studies were limited by the lack of objective outcome variables (ie, use of self-reported walking distance), small sample size, and suboptimal study design. The proposed theoretical foundation for applying an intermittent negative pressure rather than a continuous suction is related to the prevention of a vasoconstrictor mechanism, the venoarterial reflex. ${ }^{34,35}$ By applying an intermittent negative pressure, the vasoconstrictor effect of the venoarterial reflex may be circumvented. For instance, arterial blood flow velocity, skin blood flow, and skin temperature decreased after the application of a constant ambient negative pressure of $-40 \mathrm{~mm} \mathrm{Hg}$ to the lower leg and foot in healthy volunteers. ${ }^{15}$ Conversely, applying the same negative pressure intermittently (alternating 10 seconds of negative pressure and 7 seconds of atmospheric pressure) increased arterial blood flow velocity in healthy volunteers and PAD patients. ${ }^{15,16}$ In addition, a corresponding increase in skin blood flow was observed. These results seemed to suggest that the application of oscillating IVT increases macrocirculation and microcirculation, at least in some healthy volunteers and PAD patients.

There is no high-level evidence suggesting the efficacy of IVT on important outcome parameters in IC patients. Studies assessing the clinical effects of IVT are scarce, and inconclusive published data suggest that IVT offers at most a modest improvement on walking distance. In 1969, the effect of repeated periods of intermittent limb suction was examined in patients with long-standing PAD rejecting surgical treatment. ${ }^{36}$ Calf blood flow was said to increase, and 24 of 40 patients (60\%) claimed subjective benefit. An early 1990s study randomized 22 IC patients to either IVT or placebo treatment. ${ }^{37,38}$ After 25 applications administered during a period of 2 months, pain-free walking distance improved from 53 to 93 meters and maximal walking distance from 99 to 180 meters in the IVT group but not during placebo treatment. ${ }^{37} \mathrm{~A}$ recent case series suggested that IVT may facilitate wound healing. ${ }^{39}$ In this study, four patients with PAD and difficult-to-heal ulcers were treated with an 8-week intervention period of $-40 \mathrm{~mm} \mathrm{Hg}$ IVT on the lower limbs for 2 hours per day. Although these observations suggest that peripheral circulation may be enhanced with IVT, care should be taken in interpreting the results of these studies. The reported changes in walking distance with IVT were small and probably clinically insignificant. Furthermore, only a small percentage of PAD patients can feasibly attend IVT several hours per day. In this study, 57 of 177 patients assessed for eligibility (32\%) were not included because of lack of time or motivation for IVT. From the patient's viewpoint, IVT may also not be acceptable owing to additional transportation costs. Nevertheless, further studies are needed to elucidate any potential mechanisms and clinical implications of the pulsatile flow observed during IVT.

The results of this RCT are in line with a recently published study. ${ }^{40}$ In this study, IVT did not provide relief in 48 IC patients who were randomized to orally given advice of lifestyle changes (tobacco abstinence and physical activities) or IVT treatment thrice weekly for 6 weeks. Walking capacity increased in the control patients but not in the intervention patients, although group differences were not significant. In contrast to our study, blinding was not performed because of the 
Table III. Vascular Quality of Life (VascuQoL) questionnaire

\begin{tabular}{|c|c|c|c|c|c|c|c|c|}
\hline Variables & Baseline & $\begin{array}{c}6 \\
\text { weeks } \\
\end{array}$ & $\begin{array}{c}12 \\
\text { weeks }\end{array}$ & $\begin{array}{l}P \text { value } \\
\text { within } \\
\text { groups }\end{array}$ & $\begin{array}{l}\text { Change } \\
\text { from } \\
\text { baseline } \\
\text { to } \\
6 \text { weeks }\end{array}$ & $\begin{array}{l}P \text { value } \\
\text { between } \\
\text { groups }\end{array}$ & $\begin{array}{c}\text { Change } \\
\text { from } \\
\text { baseline } \\
\text { to } \\
12 \text { weeks }\end{array}$ & $\begin{array}{l}P \text { value } \\
\text { between } \\
\text { groups }\end{array}$ \\
\hline \multicolumn{9}{|l|}{$\begin{array}{c}\text { Summary } \\
\text { score }\end{array}$} \\
\hline Intervention & $5.06(3.95-5.45)$ & $5.58(4.53-5.95)$ & $5.72(4.45-6.23)$ & $<.001$ & $0.56(0.17-1.00)$ & & $0.52(0.33-1.04)$ & \\
\hline \multicolumn{9}{|l|}{ Pain } \\
\hline Control & $5.00(4.25-5.75)$ & $5.25(4.31-5.75)$ & $5.25(4.38-5.75)$ & .022 & $\begin{array}{l}0.25 \\
(-0.19 \text { to } 0.94)\end{array}$ & 0.545 & $0.25(-0.25$ to 0.75$)$ & .214 \\
\hline Intervention & $4.88(4.00-5.50)$ & $5.25(4.50-5.75)$ & $5.63(4.56-6.19)$ & .008 & 0.50 (0.00-1.00) & & $0.50(0.00-0.94)$ & \\
\hline Intervention & $4.50(3.50-5.25)$ & $5.00(4.25-5.50)$ & $5.38(4.31-5.94)$ & $<.001$ & 0.75 (0.00-1.00) & & $0.50(0.25-1.25)$ & \\
\hline \multicolumn{9}{|l|}{ Activities } \\
\hline Control & $4.26(3.69-5.25)$ & $4.94(4.03-5.72)$ & $5.25(4.25-5.63)$ & $<.001$ & $0.56(0.12-1.00)$ & .256 & $0.62(0.19-1.06)$ & .405 \\
\hline Intervention & $4.32(3.63-5.22)$ & $5.25(4.38-5.72)$ & $5.25(4.25-6.13)$ & $<.001$ & $0.75(0.41-1.25)$ & & $0.75(0.28-1.38)$ & \\
\hline \multicolumn{9}{|l|}{ Social } \\
\hline Control & 5.75 (4.00-7.00) & $5.75(4.13-7.00)$ & $6.00(4.50-7.00)$ & .232 & $0.00(0.00-0.50)$ & .583 & $0.00(-0.25$ to 1.00$)$ & .918 \\
\hline Intervention & $5.25(4.13-6.88)$ & $5.50(4.00-7.00)$ & $6.25(4.00-7.00)$ & .010 & $0.50(0.00-0.88)$ & & 0.00 (0.00-1.00) & \\
\hline \multicolumn{9}{|l|}{ Emotional } \\
\hline Control & $5.57(4.11-6.71)$ & $5.79(4.43-6.57)$ & $5.86(5.00-6.86)$ & .001 & $\begin{array}{l}0.14 \\
(-0.39 \text { to } 0.86)\end{array}$ & .170 & 0.29 (0.00-1.15) & .862 \\
\hline
\end{tabular}

lack of a placebo treatment. Furthermore, unsupervised lifestyle changes are known to be inferior to SET.

A surprising finding of this RCT is that WIQ stair and VascuQol social domains improved in the intervention group but not in the control group. We have no explanation for the observed improvements rather than chance alone. However, there were no differences between the groups after 6 and 12 weeks, indicating that these changes were not clinically relevant. Also, there tended to be more diabetic patients in the intervention group compared with the control group ( $P=.058)$. Patients with DM represent a vulnerable subgroup of patients who may respond poorly to a program of exercise rehabilitation. ${ }^{41}$ However, after adjustment for DM in a multivariate regression analysis, no significant group effects regarding walking distance, ambulatory ability, or quality of life were found (Appendix, online only).

A unique feature of this RCT was the investigation of the efficacy of IVT against a background of wellfounded and evidence-based usual care. It was not our intent to simply compare IVT with SET. Instead, this is the first study to determine the usefulness of IVT as adjunctive therapy. SET programs are widely available and reimbursement is nowadays guaranteed for all patients with IC in The Netherlands. Therefore, it is considered unethical to withhold this effective treatment from patients. Also, from a health perspective, it seems incorrect to deny patients SET as it has positive effects on the complete cardiopulmonary system and vascular risk profile (eg, body mass index and DM). ${ }^{42}$ Consequently, participating in IVT only is not a viable alternative for IC patients compared with participating in SET.

The observed effect of SET on walking distance in this $\mathrm{RCT}$ is consistent with the results of a recently published Cochrane meta-analysis indicating that SET is an effective treatment of IC and should always be offered as first-line treatment. ${ }^{10}$ Exercise-mediated gains in walking distance occur rapidly within the first 3 months of exercise rehabilitation and are maintained with further training. Overall, the primary outcome measure of MWD increased with a median of 285 meters (73\%) after 12 weeks, which reflects a clinically relevant improvement. More important, our 
results show that SET offers an increase in health-related quality of life that was seen in previous studies as well. 5,10

Strengths and weaknesses. The strength of this study is the design. All participants received an optimal strategy of usual care consisting of SET and CVRM. In addition, a control group underwent a sham treatment, whereas an intervention group underwent a possible effective IVT treatment. Both groups completed a similar number of treatment sessions, and the overall attrition rate was low (7\%). Both participants and physical therapists, who obtained outcome data, were blinded for group allocation. The most important limitation of this study is the relatively low enrollment rate (44\%) because of inclusion criteria regarding motivation, time, and additional insurance or financial resources. However, to determine the additive effect of IVT in IC patients after a regimen of SET, we had to ensure that all participants received a sufficient amount of both treatments. Another potential limitation is the absence of objective outcome parameters monitoring blood flow velocity and skin blood flow. Moreover, patients with rest pain and ulcers were excluded. Furthermore, inclusion and exclusion criteria may have created a selection bias toward patients more interested in IVT or exercise and toward those with more financial means or better access to transportation. Conversely, patients with more severe IC may have been denied study participation. Therefore, improvements within groups might be somewhat overestimated. Furthermore, the treatment effect of IVT might differ somewhat between IC patients, depending on how well they comply with SET. However, our results do not suggest such an effect. Moreover, this study did not contain isolated IVT and sham arms because, in our opinion, IVT only is not a viable alternative under current guidelines. In addition, technical aspects of IVT were based on recommendations of both the manufacturer and the IVT facility but may have been suboptimal. The IVT treatment protocol has not been validated with respect to volume or length. However, the IVT pattern (cycles of 9 seconds) and negative pressure (-50 mBar) were similar to those in other studies. $15,16,39,40$

\section{CONCLUSIONS}

IVT does not confer any additional beneficial effects on walking distance, self-reported ambulatory ability, or health-related quality of life in IC patients undergoing a standardized SET program. Consequently, IVT should not be offered to IC patients as adjunctive therapy. Further studies on any potential mechanisms and clinical implications of IVT are needed.

We thank all vascular surgeons, physical therapists, and patients for participating in this study. We also appreciate Been Kliniek Eindhoven and Fysiotherapie Airborne Eindhoven for providing the Vacumed device for use in this study.

\section{AUTHOR CONTRIBUTIONS}

Conception and design: DH, LG, MS, JT

Analysis and interpretation: DH, HF, BD, LG, EC, MS, JT

Data collection: $\mathrm{DH}, \mathrm{BD}$

Writing the article: $\mathrm{DH}$

Critical revision of the article: HF, BD, LG, EC, MS, JT

Final approval of the article: DH, HF, BD, LG, EC, MS, JT

Statistical analysis: $\mathrm{DH}$

Obtained funding: Not applicable

Overall responsibility: JT

\section{REFERENCES}

1. Fowkes FG, Rudan D, Rudan I, Aboyans V, Denenberg JO, McDermott MM, et al. Comparison of global estimates of prevalence and risk factors for peripheral artery disease in 2000 and 2010: a systematic review and analysis. Lancet 2013:382:1329-40.

2. Conte MS, Pomposelli FB, Clair DG, Geraghty PJ, McKinsey JF, Mills JL, et al. Society for Vascular Surgery practice guidelines for atherosclerotic occlusive disease of the lower extremities: management of asymptomatic disease and claudication. J Vasc Surg 2015;61(Suppl):2S-41S.

3. Gerhard-Herman MD, Gornik HL, Barrett C, Barshes NR, Corriere MA, Drachman DE, et al. 2016 AHA/ACC Guideline on the Management of Patients With Lower Extremity Peripheral Artery Disease: a report of the American College of Cardiology/American Heart Association Task Force on Clinical Practice Guidelines. Circulation 2017;135:e726-79.

4. Aboyans V, Ricco JB, Bartelink ME, Bjorck M, Brodmann M, Cohnert T, et al. 2017 ESC Guidelines on the Diagnosis and Treatment of Peripheral Arterial Diseases, in collaboration with the European Society for Vascular Surgery (ESVS). Eur J Vasc Endovasc Surg 2018;55:305-68.

5. Nicolai SP, Teijink JA, Prins MH. Multicenter randomized clinical trial of supervised exercise therapy with or without feedback versus walking advice for intermittent claudication. J Vasc Surg 2010;52:348-55.

6. Gardner AW, Parker DE, Montgomery PS, Scott KJ, Blevins SM. Efficacy of quantified home-based exercise and supervised exercise in patients with intermittent claudication: a randomized controlled trial. Circulation 2011;123:491-8.

7. Gardner AW, Montgomery PS, Parker DE. Optimal exercise program length for patients with claudication. J Vasc Surg 2012;55:1346-54.

8. Gardner AW, Parker DE, Montgomery PS, Blevins SM. Stepmonitored home exercise improves ambulation, vascular function, and inflammation in symptomatic patients with peripheral artery disease: a randomized controlled trial. J Am Heart Assoc 2014;3:e001107.

9. Fakhry F, van de Luijtgaarden KM, Bax L, den Hoed PT, Hunink MG, Rouwet EV, et al. Supervised walking therapy in patients with intermittent claudication. J Vasc Surg 2012;56: $1132-42$.

10. Hageman D, Fokkenrood HJ, Gommans LN, van den Houten MM, Teijink JA. Supervised exercise therapy versus home-based exercise therapy versus walking advice for intermittent claudication. Cochrane Database Syst Rev 2018:4:CD005263.

11. Vikatmaa P, Juutilainen V, Kuukasjarvi P, Malmivaara A. Negative pressure wound therapy: a systematic review on effectiveness and safety. Eur J Vasc Endovasc Surg 2008;36: 438-48. 
12. Dumville JC, Land L, Evans D, Peinemann F. Negative pressure wound therapy for treating leg ulcers. Cochrane Database Syst Rev 2015;7:CD011354.

13. Weyergans High Care AC. Available at: https://vacumed.de/ en/vacumed-imprint.html. Accessed December 1, 2018.

14. WittCare. Available at: https://wittcare.com. Accessed December 1, 2018.

15. Sund by OH, Hoiseth LO, Mathiesen I, Jorgensen JJ, WeedonFekjaer $\mathrm{H}$, Hisdal J. Application of intermittent negative pressure on the lower extremity and its effect on macro- and microcirculation in the foot of healthy volunteers. Physiol Rep 2016:4:e12911.

16. Sundby $\mathrm{OH}$, Hoiseth LO, Mathiesen I, Weedon-Fekjaer $\mathrm{H}$, Sundhagen JO, Hisdal J. The acute effects of lower limb intermittent negative pressure on foot macro- and microcirculation in patients with peripheral arterial disease. PLOS One 2017;12:e0179001.

17. Schulz KF, Altman DG, Moher D. CONSORT 2010 statement: updated guidelines for reporting parallel group randomised trials. BMJ 2010;340:c332.

18. Gardner AW, Skinner JS, Cantwell BW, Smith LK. Progressive vs single-stage treadmill tests for evaluation of claudication. Med Sci Sports Exerc 1991;23:402-8.

19. Lauret GJ, Gijsbers HJ, Hendriks EJ, Bartelink ML, de Bie RA, Teijink JA. The ClaudicatioNet concept: design of a national integrated care network providing active and healthy aging for patients with intermittent claudication. Vasc Health Risk Manag 2012;8:495-503.

20. Fokkenrood HJ, Lauret GJ, Scheltinga MR, Spreeuwenberg C, de Bie RA, Teijink JA. Multidisciplinary treatment for peripheral arterial occlusive disease and the role of eHealth and mHealth. J Multidiscip Healthc 2012;5:257-63.

21. Hageman D, van den Houten MM, Spruijt S, Gommans LN, Scheltinga MR, Teijink JA. Supervised exercise therapy: it does work, but how to set up a program? J Cardiovasc Surg (Torino) 2017:58:305-12.

22. Merry AH, Teijink JA, Jongert MW, Poelgeest A, van der Voort SS, Bartelink ME, et al. Practice guideline. Symptomatic peripheral arterial disease. Amersfoort, The Netherlands: Royal Dutch Society for Physical Therapy; 2014.

23. Kruidenier LM, Nicolai SP, Willigendael EM, de Bie RA, Prins $\mathrm{MH}$, Teijink JA. Functional claudication distance: a reliable and valid measurement to assess functional limitation in patients with intermittent claudication. BMC Cardiovasc Disord 2009;9:9.

24. Nicolai SP, Viechtbauer W, Kruidenier LM, Candel MJ, Prins $\mathrm{MH}$, Teijink JA. Reliability of treadmill testing in peripheral arterial disease: a meta-regression analysis. J Vasc Surg 2009;50:322-9.

25. Butland RJ, Pang J, Gross ER, Woodcock AA, Geddes DM. Two-, six-, and 12-minute walking tests in respiratory disease. Br Med J (Clin Res Ed) 1982;284:1607-8.

26. Montgomery PS, Gardner AW. The clinical utility of a sixminute walk test in peripheral arterial occlusive disease patients. J Am Geriatr Soc 1998:46:706-11.

27. Regensteiner JG, Steiner JF, Panzer RJ, Hiatt WR. Evaluation of walking impairment by questionnaire in patients with peripheral arterial disease. J Vasc Med Biol 1990;2: 142-52.

28. Verspaget M, Nicolai SP, Kruidenier LM, Welten RJ, Prins MH, Teijink JA. Validation of the Dutch version of the Walking
Impairment Questionnaire. Eur J Vasc Endovasc Surg 2009;37:56-61.

29. Nicolai SP, Kruidenier LM, Rouwet EV, Graffius K Prins $\mathrm{MH}$, Teijink JA. The Walking Impairment Questionnaire: an effective tool to assess the effect of treatment in patients with intermittent claudication. J Vasc Surg 2009;50:89-94.

30. Morgan MB, Crayford T, Murrin B, Fraser SC. Developing the Vascular Quality of Life Questionnaire: a new disease-specific quality of life measure for use in lower limb ischemia. J Vasc Surg 2001;33:679-87.

31. Frans FA, van Wijngaarden SE, Met R, Koelemay MJ. Validation of the Dutch version of the VascuQol questionnaire and the Amsterdam Linear Disability Score in patients with intermittent claudication. Qual Life Res 2012;21:1487-93.

32. Conijn AP, Loukachov VV, Bipat S, Koelemay MJ. Test-retest reliability and measurement error are excellent for the Dutch version of the VascuQol Questionnaire in patients with intermittent claudication. Eur J Vasc Endovasc Surg 2015:50:502-5.

33. EuroQol-a new facility for the measurement of healthrelated quality of life. Health Policy 1990;16:199-208.

34. Henriksen O. Local reflex in microcirculation in human subcutaneous tissue. Acta Physiol Scand 1976;97:447-56.

35. Skagen K, Henriksen O. Changes in subcutaneous blood flow during locally applied negative pressure to the skin. Acta Physiol Scand 1983;117:411-4.

36. Smyth CN. Effect of suction on blood-flow in ischaemic limbs. Lancet 1969;2:657-9.

37. Himmelstrup H. Himmelstrup B, Mehlsen J. Trap-Jensen J. Effects of Vacusac in intermittent claudication: a controlled cross-over study. Clin Physiol 1991;11:263-9.

38. Mehlsen J, Himmelstrup H, Himmelstrup B, Winther K. TrapJensen J. Beneficial effects of intermittent suction and pressure treatment in intermittent claudication. Angiology 1993:44:16-20.

39. Sundby $\mathrm{OH}$, Hoiseth LO, Mathiesen I, Jorgensen JJ, Sundhagen JO, Hisdal J. The effects of intermittent negative pressure on the lower extremities' peripheral circulation and wound healing in four patients with lower limb ischemia and hard-to-heal leg ulcers: a case report. Physiol Rep 2016; $4:$ e12998.

40. Afzelius P, Molsted S, Tarnow L. Intermittent vacuum treatment with VacuMed does not improve peripheral artery disease or walking capacity in patients with intermittent claudication. Scand J Clin Lab Invest 2018;78:456-63.

41. Gardner AW, Parker DE, Montgomery PS, Blevins SM Diabetic women are poor responders to exercise rehabilitation in the treatment of claudication. J Vasc Surg 2014:59:1036-43.

42. Sakamoto S, Yokoyama N, Tamori Y, Akutsu K, Hashimoto H, Takeshita S. Patients with peripheral artery disease who complete 12-week supervised exercise training program show reduced cardiovascular mortality and morbidity. Circ J 2009;73:167-73.

Submitted Mar 21, 2019; accepted Aug 12, 2019.

Additional material for this article may be found online at www.jvascsurg.org. 


\section{APPENDIX (online only).}

Multivariate regression analysis adjusted for diabetes mellitus (DM)

Group effect regarding MWD adjusted for DM After 6 weeks: $\beta \pm \mathrm{SE}=-86 \pm 66 ; P=.191$ After 12 weeks: $\beta \pm \mathrm{SE}=-131 \pm 82 ; P=.108$ Group effect regarding FWD adjusted for DM After 6 weeks: $\beta \pm \mathrm{SE}=-42 \pm 46 ; P=.368$ After 12 weeks: $\beta \pm \mathrm{SE}=-132 \pm 88 ; P=.133$

Group effect regarding 6MWT adjusted for DM After 6 weeks: $\beta \pm \mathrm{SE}=11 \pm 17 ; P=.512$ After 12 weeks: $\beta \pm \mathrm{SE}=23 \pm 15 ; P=.125$
Group effect regarding total WIQ score adjusted for DM After 6 weeks: $\beta \pm \mathrm{SE}=0.028 \pm 0.042 ; P=.503$ After 12 weeks: $\beta \pm \mathrm{SE}=0.024 \pm 0.042 ; P=.564$ Group effect regarding summary VascuQol score adjusted for DM

After 6 weeks: $\beta \pm \mathrm{SE}=0.296 \pm 0.187 ; P=.113$ After 12 weeks: $\beta \pm \mathrm{SE}=0.087 \pm 0.170 ; P=.611$

$F W D$, Functional treadmill walking distance; $M W D$, maximal treadmill walking distance; 6MWT, 6-minute walk test; SE, standard error; VascuQol, Vascular Quality of Life questionnaire; WIQ, Walking Impairment Questionnaire. 